\title{
Correspondence
}

\section{TWO CORRECTIONS}

To the Editor-in-Chief.

Dear Sir,

"Morbid Jealousy: Some Clinical and Social Aspects of a Psychiatric Symptom",

An article of mine under the above titleappeared in the July, 1961 issue of the Journal of Mental Science, pp. 687-753. The paper includes an appendix with 81 case histories. Unfortunately one of these cases, number $11 \mathrm{a}$ in the text, is numbered 12 in the appendix; for each subsequent case history there is then a failure of correspondence between text and appendix which must be confusing to the uninstructed reader. I should be most grateful if you could include a reference to it in the Journal as soon as may be convenient. I should also be glad if the following acknowledgment, also lost at the proof-stage, could be mentioned: "For access to many patients and case histories the author is grateful to the physicians on the staff of the Maudsley and Bethlem Royal Hospitals and especially to Dr. D. L. Davies."

23 October, 1961.

Michael SHEPHERD.

To the Editor-in-Chief.

Dear Sir,

"Environmental and Hereditary Factors in the Schizophrenias of Old Age"

In our article so titled, which appeared in the July issue, 1961, there appeared a number of errors and omissions. The most important of these is the use of the term "primary" to describe the delusions of our paraphrenic cases. Further consideration had led us to the conclusion that true primary delusions far from being a feature of the illness, rarely occur, and that the term "paranoid" would be more appropriate. Unfortunately, this correction did not appear. The matter is important, since the presence of primary delusions is in general regarded as unequivocal evidence of schizophrenia proper while paranoid delusions do of course occur in a wide variety of conditions.

The other errors concern the Tables. In Table II the title should have read "Mode of admission to hospital among unmarried and widowed patients in Stockholm". Married patients are excluded because they are relatively uncommon among the paraphrenics.

Table IV appears on page 664 , but the main reference to it in the text is on page 652 , where the proportion of patients living alone is under discussion. Here again married women, as well as men, are omitted to make the comparison between the paraphrenic and affective groups more valid.

Finally, Table $\mathrm{V}$ should be read in connection with the paragraph immediately above it, referring to "social isolation". The subsequent passage refers to a mixed group of unmarried affective and organic patients, selected from the available material (1951-1955) because good accounts of the premorbid personality existed.
23 October, 1961.
MARTIN Roth.
D. W. K. KAY.

[We regret these errors, which were unfortunately left uncorrected owing to circumstances connected with the change in the management of the Journal early last year.-Editors.] 